\title{
The Impacts of Fertilizer Credit on Crop Production and Income in Ethiopia
}

\author{
By \\ Tomoya Matsumoto \\ and \\ Takashi Yamano
}

December 2010

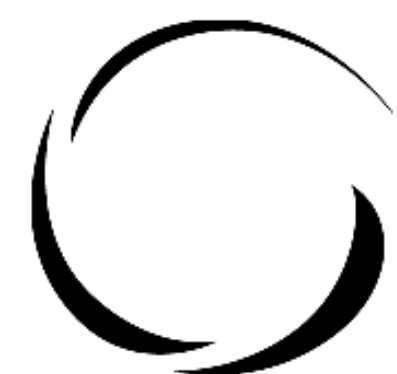

GRIPS

National Graduate institute FOR POLICY STUDIES

National Graduate Institute for Policy Studies

7-22-1 Roppongi, Minato-ku,

Tokyo, Japan 106-8677 


\title{
The Impacts of Fertilizer Credit on Crop Production and Income in
}

\author{
Ethiopia \\ Tomoya Matsumoto $^{1}$ and Takashi Yamano ${ }^{2}$
}

\begin{abstract}
In this chapter, we evaluate the impact of fertilizer credit on crop choice, crop yield, and income using two-year panel data of 420 households in rural Ethiopia. The fertilizer credit is found to increase input application for crop production. As a consequence, it has a substantial impact on the yield of teff. We also find that the impact on net crop income per cultivated area and also on per capita income is marginal because of the low profitability due to the low output price and high input cost of agricultural production.
\end{abstract}

Key words: Input Credit, Fertilizer Policy, Agricultural Technology, Crop Production, Ethiopia

\footnotetext{
${ }^{1}$ National Graduate Institute for Policy Studies, Japan

${ }^{2}$ Foundation for Advanced Studies on International Development, National Graduate Institute for Policy Studies, Japan
}

Correspondent author, Tomoya Matsumoto, National Graduate Institute for Policy Studies, 7-22-1, Roppongi, Minato-ku, Tokyo, 106-8677, Japan tmatsumoto@grips.ac.jp 


\section{Introduction}

Ethiopia is not only one of the poorest countries in the world, but also one of the most populated countries: it is the $14^{\text {th }}$ largest in the world and the second largest in Africa. To feed the large and growing population, agricultural production has to be increased by improving the agricultural productivity per land area because most of accessible fertile lands have been cultivated. To improve the agricultural productivity, the Ethiopian government has been implementing policies under the Sustainable Development and Poverty Reduction Program (SDPRP) and, more recently, the Plan for Accelerated and Sustained Development to End Poverty (PASDEP). In particular, Ethiopian regional governments initiated a 100 percent credit guarantee scheme on farmers' fertilizer purchases in 1994. Currently, it is said that about 90 percent of fertilizer is delivered on credit at below-market interest or even at zero interest. Subsequently, the total fertilizer use has increased from 250,000 tons in 1995 to 400,000 tons in 2008 (Spielman et al. 2010).

The credit scheme in Ethiopia, however, raises some concerns, as many other top-down credit schemes in developing countries do. First, the input distribution tied to credit may limit the emergence of private sector retailers, as pointed out by Jayne et al. (2003). Second, the public input distribution tends to deliver inputs, which are of low-quality and arrive, too late. Spielman et al. (2010), for instance, quote a study which finds that half of the surveyed Ethiopian smallholders reported that their fertilizer arrived after planting, and 25 percent complained of the poor quality of the fertilizer they received. Third, the application of standard packages to very diverse environments in Ethiopia may lead to a low efficiency of fertilizer use. Thus, it is very important to 
evaluate the impact of the fertilizer credit scheme on the farm productivity and welfare of the farmers. Fortunately, there are large variations in the use of credit access across regions and over time, and such variations provide an opportunity to evaluate the effects of the credit scheme on crop production and income using panel data. ${ }^{1}$

The purpose of this chapter, therefore, is to evaluate the impact of the credit scheme on the inorganic fertilizer application, the crop yields, and the crop income, by using a two-year panel data of 420 households in rural Ethiopia. The major obstacle to identifying a causal impact of a credit scheme is that farmers voluntarily participate in such schemes rather than being randomly assigned. To overcome or mitigate the possible self-selection biases, we take advantage of the panel data by controlling for unobserved household characteristics. The results in this chapter suggest that the credit increases inorganic fertilizer use per ha but has only limited impacts on crop yields. The limited impacts are likely due to low adoption rates of high-yielding varieties which should ideally accompany with the inorganic fertilizer use. We find that only about 10 percent of our sampled farmers cultivate high-yielding maize or wheat varieties, while others apply the inorganic fertilizer on local varieties of maize and wheat. As a result, the credit has little impacts on crop income.

This paper is organized as follows: Section 4.2 explains the changes in

\footnotetext{
1 It is worth noting that the inputs provided by regional governments or cooperatives on credit are highly subsidized and, hence, they can provide those inputs at very low or even zero interest rate. Because of the high inflation rate in Ethiopia, the low interest rate means that the real interest rate is negative. Hence, "the input credit" has two different effects. The first is the effect of easing credit constraints by obtaining the credit for the purchase of the inputs. The second is the effect through the change in relative prices of the inputs. In this paper, the effect of "the input credit" means the mixed effect of those two components.
} 
inorganic fertilizer policies in Ethiopia and its current situation. Section 4.3 describes the household survey data used for this study. Section 4.4 presents the empirical findings on the effect of the provision of input credit on inorganic fertilizer application, crop yield, and income. Finally, we discuss the policy implications based on the results we obtained.

\section{Fertilizer and Credit Policies in Ethiopia}

Even when new technologies appear to be very profitable to crop scientists and economists, farmers may not adopt them (Feder et al., 1985; Munshi, 2008; Duflo et al. 2008). One of major constraints for small-scale farmers to adopt agricultural technologies is credit (e.g. Croppenstedt et al., 2003; Gine and Klonner, 2006; Zerfu and Larson, 2010) since cash resources are generally insufficient to cover high-yielding variety seeds and chemical fertilizer purchase for small-scale farmers at the planting season. Despite the importance of credit, the private financial sector is underdeveloped especially in rural areas due to high and correlated risks in smallholder agriculture, asymmetric information between borrower farmers and credit providers as well as incomplete enforcement of credit contracts. Thus, public intervention to credit market has been justified for on the purpose of improving formal credit access of small-scale farmers. In spite of the potential of public intervention in on financial services for small-scale farmers, however, such an intervention has to be considered with caution because there are some drawbacks. Firstly, it may crowd out private financial service providers that would be more efficient than public providers. Secondly, a certain type of 
public intervention such as agricultural lending and input credit is often used as an instrument of political capture and, hence, persistently continued even when it does not have measurable impact on agricultural output (Cole 2004). ${ }^{2}$

Historically in Ethiopia, a government parastatal called Agricultural Input Supply Enterprise (AISE) controlled the importation, distribution, and pricing of inorganic fertilizer during the Dergue regime (1974-1987). The Ethiopian government began curtailing the operation of the official state marketing board under foreign aid -conditionality agreements with donors since 1993 . The private sector was allowed to participate in fertilizer importation and distribution following the issuance of the National Fertilizer Policy (Jayne et al., 2003). As a result, some private companies entered into the sector. The government, however, gave favorable treatments toward regional holding companies which competed with the private companies. The favorable treatments included the allocation of foreign exchanges for the importation and distribution of fertilizer through government administered credit to farmers. Because of these favorable treatments toward regional holding companies, private companies found it impossible to compete with them, and all of the private companies exited from the market by 2000. Since then, the distribution system of inorganic fertilizer has been dominated by AISE and a small number of the regional holding companies (Spielman et al., 2010).

In recent years, under the SDPRP and the PASDEP, the government has started providing substantial resources to the regional governments to enhance

2 Conning and Udry (2007) provide a comprehensive review of financial sector in rural areas of low-income countries. 
agricultural production. To attain several goals of the PASDEP, the government has been restructuring and strengthening cooperatives. Corresponding to the government action, the number of members participating in cooperatives has increased rapidly, and hence the cooperatives have gained significant more power than before. Since 2004, several cooperative unions have started to operate in the distribution of agricultural inputs at the regional level. The farmers' cooperatives have replaced the AISE in the importation and distribution of fertilizer. The cooperatives currently provide about 56 percent of the total supply of fertilizer. The cooperatives provide short-term credit on fertilizer purchases to farmers under a 100 percent credit guarantee scheme by the regional governments. The largest source of such agricultural credit is the Commercial Bank of Ethiopia (CBE) serving more than 2.5 million farmers. As of 2006, two regional holding companies (Ambassel and Wondo), the fertilizer parastatal (AISE), and cooperative unions accounted for 100 percent of fertilizer imports and local distributions.

Partly due to the credit scheme, as mentioned earlier, the total fertilizer consumption in Ethiopia has increased from 250,000 tons in 1995 to 400,000 tons in 2008 (Spielman et al., 2010). However, the intensity of the fertilizer use has increased only marginally over the past decade from 31 kilograms per ha in 1995 to 36 kilograms per ha in 2008. The increase in the total fertilizer consumption has been absorbed largely by area expansion. Moreover, despite the huge PASDEP demonstration programs, only 37 percent of farmers were using inorganic fertilizer (Spielman et al., 2010). A study cited in Spielman et al. (2010) found that half of the farmers surveyed for the study reported that the fertilizer arrived after planting. It also found that 32 percent of the surveyed farmers reported underweight bags, and 25 percent complained 
of the poor quality. Also, unlike neighboring countries such as Kenya, Ethiopia does not offer fertilizer in smaller packages that could be used by smallholders or in different formulations needed for different types of agro-climates, soils, and crops. Thus, the application of standard packages to vastly diverse environments in Ethiopia and the non-optimal use of these packages by farmers lead to low fertilizer production efficiency and returns to investment. Much of the discussion on the effects of the fertilizer credit production efficiency, however, is based on secondary macro data or from small cross-sectional case studies. There is a need for a rigorous impact study that is based on a wide area which relies on individual panel data set. Panel data enables one by which we can observe the changing behaviors of the same farm households with and without fertilizer credit. The drastic changes in the distributions of inorganic fertilizer in recent years create substantial variations across regions in access to input credit. Such variations provide us an opportunity to evaluate the effect of the input credit on input use, crop yields, and farmers' welfare in Ethiopia.

\section{Data and Descriptive Statistics}

\subsection{Data}

The data used in this paper have been collected through the RePEAT household survey in rural Ethiopia by the FASID/GRIPS research team in 2004 and 2006. The survey covers 42 villages in 11 zones located within a $400 \mathrm{~km}$ radius from Addis Ababa. In each village, 10 households were randomly selected in 2004 and 
re-interviewed in $2006 .^{3}$ All the households in the survey engage in agriculture. The survey villages belong to three regions; Amhara, Oromia, and SNNP. Out of the 42 survey villages, 21 are located in Oromia, which is the largest region surrounding Addis Ababa and has several different agro-ecological zones. Hence, we divide the Oromia region into three sub-regions (SoutheastSouth East, Central, and West) with consideration of the differences in their farming systems for the following analyses. We present the summary statistics of the sample households by region in Table 1.

The proportion of households using inorganic fertilizer varies from 33 percent in the Amhara region to 91 percent in Oromia Central. On average, about two-thirds of the sample households applied at least some inorganic fertilizer. This is a high proportion by African standards. The main reason for the high inorganic fertilizer use is the credit that farmers receive. In Table 1, we find that about 46 percent of the sample farmers received credit in 2004, and that the proportion increased to 63 percent in 2006. The South East and Central regions of Oromia have high proportions of farmers receiving credit. This is likely to reflect the high intensities of government investment and effort in delivering public interventions on input credit by the regional government. Partly because of the credit programs in these locations, the amounts of inorganic fertilizer applied on crop production are very high in these sub regions. The amount of inorganic fertilizer applied is about 121 kilograms per ha in 2004 and 109 kilograms per ha in 2006 in the South East region of Oromia and is 59 kilograms per ha and 68 kilograms per ha in the West region. In contrast, in the Amhara region, where only less

\footnotetext{
${ }^{3}$ In the following analyses, 12 out of 420 households are dropped due to missing information on variables of interest in the 2004 data while 9 households are dropped due to attrition in the 2006 survey.
} 
than 20 percent of the sample households received credit in 2004 and 2006, the level of inorganic fertilizer application is at the lowest among the sample regions. Thus, we suspect that the credit access has significant impacts on the use and amount of fertilizer application. We need to be cautious about the causal relationship between the credit and fertilizer use because it is possible that the causality goes the other direction. The provision of credit by the regional credit programs might be provided in regions where fertilizer demand is already high and, hence, its use is effective.

\subsection{Descriptive statistics}

To identify the causal relationship between credit and fertilizer use, we divide the samples into four groups based on their access to credit: Non Recipients, Late Recipients, Early Recipients, and Continuous Recipients. Non Recipients include households who did not obtain credit in both 2004 and 2006. Late Recipients include households who did not obtain credit in 2004 but obtained it in 2006. In contrast, Early Recipients include households who obtained credit in 2004 but did not in 2006. Finally, Continuous Recipient includes households who obtained credit in both 2004 and 2006. The examination of the fertilizer applications of these groups, may indicate how much the fertilizer application by these groups will show how much fertilizer use changes when the credit access changes over time at the household level.

In Table 2, we find that, among the Late Recipients group, the fertilizer application increases by 37 kilograms per ha, from 54 kilograms per ha in 2004 to 91 kilograms per ha in 2006, when they gained access to credit in 2006. The change is statistically significant at the 1 percent level. Furthermore, since there is a downward 
trend in the fertilizer use over the years among sample households, the 'true' effect of Because we find the increase in the fertilizer application among the same households over time, this increase is likely to be caused by the credit access could be larger than 37 kilograms per ha among the Late Recipient households.. On the other hand, among the Early Recipients group, we find a decrease in fertilizer application by 19 kilograms per ha, as they lost their access to credit from 2004 to 2006. Among the other two groups, Non Recipients and Continuous Recipients, we find slight declines in fertilizer applications, but the absolute amount. Thus, it seems that there is a downward trend in the fertilizer use over the years among sample households. This suggests that, in the absence of fertilizer used by Continuous Recipients is several times the amount used by Non Recipients. The real causal impact of these support the hypothesis that credit is very important for fertilizer purchase and use the credit access could be larger than the 37 kilograms per ha among the Enter households.

To investigate the impacts of the credit program on crop yields, we first look at the crop choice of the farmers with and without credit. In Table 3, we present the crop choice in 2004 and 2006 grouped by the credit status, as in Table 2. What should be noted in this table is that proportions of farmers who cultivate high-yielding varieties (HYV) are very low in Ethiopia. For instance, the proportion of the sample farmers who cultivate HYV maize is only 7 and 9 percent in 2004 and 2006, respectively. Likewise, the proportion of the sampled farmers who cultivate HYV wheat is only 11 and 9 percent in 2004 and 2006, respectively. Even when we disaggregate the sampled farmers by the credit access status, we do not find a high proportion of HYV adopters among those who received credit. For instance, only 7 percent of Continuous Recipients 
cultivated HYV maize in both 2004 and 2006. Among the same Continuous Recipients, we find that about 30 percent of them cultivate local maize. Thus, among maize producers in this group, only 20 percent of them cultivate HYV maize. Among Late Recipient households who did not receive credit in 2004 but received it in 2006, we find an increase in the proportion of those who cultivate HYV maize from 6 percent in 2004 to 17 percent in 2006 and a decline in the proportion of those who cultivated local maize from 41 percent in 2004 to 29 percent in 2006. Thus, it seems that the HYV maize adoption rate responds to the availability of the fertilizer credit to some extent among this group, although the proportion of the maize producers who adopt HYV maize is only 37 percent even among this group in 2006 when they receive the credit.

In contrast, the HYV adoption rate does not respond to the availability of the fertilizer credit among wheat producers. Among the Late Recipient group, the proportion of the farmers who adopt HYV wheat is 13 percent before receiving the credit and just at 12 percent even when they receive the credit. Among the same group, about 40 percent of the farmers produce local wheat, thus the HYV wheat adoption rate remains about 22 percent. With low adoption rates of high-yielding varieties of maize and wheat, it is unlikely that the fertilizer credit program would havehas large impacts on the crop yields because local varieties have low response rates to fertilizer use in general.

To examine the impacts of the credit on the crop yields, we present the average yields of major cereal crops by the credit is used or access in Table 4 . In the table, we find that the average yields of teff and local wheat are higher when the credit is available than it is not available. The overall average of the teff yield is 665 kilograms 
per ha. It is 553 kilograms per ha when credit is not available, while it increases to 704 kilograms per ha when credit is available. The difference of these two is about 151 kilograms per ha, which is a 27 percent increase. Credit The credit also increases the average yield of local wheat from 808 kilograms per ha to 1,072 kilograms per ha. The increase is about 264 kilograms per ha, which is a 33 percent increase. Thus, it seems that the credit access increases the yields of teff and local wheat, although the average yields of these crops with credit are still at a very low level by international standards. The credit, however, is expected to increase the yields of HYV varieties to a greater extent because the credit increases the inorganic fertilizer application on the HYV varieties which are much more fertilizer responsive. Indeed, we find higher yields on HYV maize and wheat when the credit is available than when it is not available in Table 4, although differences in the yields are small in magnitude and statistically insignificant. The weak impacts of the credit on the average yields of these HYV crops suggest some problems with the HYV varieties, such as unsuitability to the particular site, inappropriate application of inorganic fertilizer on the HYV varieties or poor quality of these HYV seeds. To confirm and further understand these findings, we need a more rigorous approach. In the following sections, we use multiple regression models in which we can control for external factors such as agro-ecological conditions and farmer characteristics in addition to the credit availability of credit.

\section{Empirical Models and Variables}

The main purpose of this chapter is to identify the impacts of the credit access 
to public sector fertilizer credit on the inorganic fertilizer application, yields, and income. We use a binary indicator representing whether a household obtains the input credit in each of the two years. The major issue on estimating such impacts is the endogeneity of the credit access variable. Households who receive credit may have different characteristics than those who do not receive credit. Those who receive credit may be more capable or located in more fertile areas than those who do not receive credit. This can create a spurious correlation between the credit use and the crop yields or income. To overcome this issue, we employ the difference-in-differences approach with time-variant control variables. The basic empirical model can be written as a simple regression form:

$$
y_{i j t}=\alpha d_{i j t}+\beta x_{i j t}+\delta_{i}+v_{j t}+\varepsilon_{i j t},
$$

where $y_{i j t}$ is the yield or the income of household $i$ in region $j$ at time $t ; d_{i j t}$ is a dummy variable taking 1 if household $i$ received the credit at time $t ; x_{i j t}$ is a vector of household characteristics; $\delta_{i}$ is a time-invariant household component which represents unobserved household characteristics; $v_{j t}$ is a time-variant region component; $\varepsilon_{i j t}$ is household specific transitory shock that has mean zero at each time $t$. Our focus is to estimate the coefficient of the credit dummy, that is, $\alpha$. By estimating the household fixed effects model, we can eliminate the time-invariant household component, $\delta_{i}$, which could be correlated with the independent variables including the credit dummy, $d_{i j t}$.

One drawback of the household fixed effects model is that all of the time-invariant household characteristics would be excluded from the model, along with 
$\delta_{i}$. Thus, we are unable to estimate the coefficients of some of the important household characteristics, such as the education level and the gender of the household head, and the soil fertility because we have only one time observation of the soil fertility. Despite the drawback, however, we prefer estimating the household fixed effects model because our purpose is to identify the impacts of the input credit program on the agricultural productivity and income.

\section{Results}

\subsection{Determinants of use of access to fertilizer credit}

We estimate the determinants of the use of access to fertilizer credit and present the results in Table 5, while applying a village and -year fixed-effects model. Household characteristics and household head's characteristics are included as the covariates. The results are obtained from the conditional logit estimation method. Thus, the identification of the parameters of interest relies on within-village variation. The result shows that the land size has a positive and significant impact on the credit access but the value of asset holdings does not have a significant impact. It appears that cooperatives and public banks provide the fertilizer credit based on the needs of the recipients, represented by land size, but not based on the repayment ability of the recipients, because if they are concerned with the repayment ability, the value of asset holdings should have a significant impact on the credit access. In addition, the cooperatives and public banks do not seem to be gender neutral, judging from the negative and significant coefficient of female-headed household dummy, which 
indicates that female headed households are less likely to receive the fertilizer credit than male-headed households.

\subsection{Impacts on the fertilizer application}

Next, in Table 6, we present the results from the household fixed effects models on the quantity of inorganic fertilizer application. The results are very similar to what we find in Table 2. In fact, when we estimate a simple model with the credit dummy variable and dummies for regions, survey years, and interaction terms between them, column (1), we find that the impact of the credit is 36 kilograms per ha, which is almost identical to the increase in fertilizer use among the Late Recipient group, 36.5 kilograms per ha, in Table 2. The estimated coefficient of the credit variable remains at the same level, 35.1 kilograms per ha, even when we add some time-varying household characteristics to the model. Because the average fertilizer application level is about 70 kilograms per ha, according to Table 2, a $35 \mathrm{~kg}$ per ha increase is a 49 percent increase in the amount application. Because we include interaction terms of regions and survey years in the model, it is unlikely that the unobserved regional level shocks are correlated with the credit variable, thereby generating biased estimators.

The estimated coefficients of the other independent variables are consistent with our expectations. Land size has a negative coefficient on the quantity of inorganic fertilizer used use per ha, indicating that inorganic fertilizer is more intensely applied among small land holders than large land holders. The size of the estimated coefficient indicates that the inorganic fertilizer application increases by 0.46 kilograms when the 
land size decreases by one percent. Asset holding also has a significant impact on the inorganic fertilizer application: a one percent increase in the asset holding increases the inorganic fertilizer application by 0.16 kilograms per ha. Thus, even when credit is available, the asset holding matters on the inorganic fertilizer application. This suggests that at least some households are still facing credit constraints and that access to cash on hand determines how much fertilizer they apply on crops. Finally, we find that the number of family members has a negative coefficient on the fertilizer application, suggesting that the family workers and the inorganic fertilizer are substitutes. One additional family worker replaces about 5 kilograms of inorganic fertilizer per ha.

\subsection{Impacts on crop yields and income}

To measure the impact of the credit access on crop yields, we estimate the yield functions of three major crops, teff, maize, and wheat, in our survey areas with the household fixed effects model (Table 7). The results indicate that the credit access has a significant impact on teff but not on maize and wheat. The estimated coefficient of the credit is 0.37 on teff, suggesting that the teff yield increases by 37 percent if credit is provided. This increase is due to the increased inorganic fertilizer use as we found find earlier. On the maize and wheat yields, we do not find any significant impacts. As we can see in Chapter 3 in this book, the farm-gate price of teff is much higher than the farm-gate prices of maize and wheat: the farm-gate price of teff is USD 22.6 and 32.6 per 100 kilograms in 2004 and 2006, respectively, while the farm-gate price is USD 10.9 and 13.0 for maize and is USD 14.0 and 20.8 for wheat in 2004 and 2006, 
respectively. Thus, although the return also depends on returns to fertilizer use is an important consideration, it seems more profitable to apply inorganic fertilizer on teff than on maize or wheat. This could be why we find a large impact of the credit on the teff yields yield but not on the maize and wheat yields.

Regarding the impact of the credit on income, we present the results on the crop income per ha in Table 8. In the table, we find no impact of the credit on income: the estimated coefficient of the credit on the crop income per ha is -0.037 and the t-statistics is not even close to a significant level. Crop The crop income is calculated by subtracting the input cost, which includes the costs of credit, fertilizer, other chemicals, and hired labor, from the value of crop production. The value of crop production is the sum of the values, evaluated at the market prices, of all crops. Because the credit access increases the yield of teff by 37 percent among the sample households, it should also increase the total value of crop production to some extent. However, the increased yields come with increased costs of fertilizer which are covered by the credit repayment. Thus, it seems that the cost of fertilizer largely offsets the increased revenue.

\section{Conclusions}

In this chapter, we evaluate the impact of the fertilizer credit on input use for crop production, crop choice, crop yield, and household income using a two-year panel data set of 420 households in rural Ethiopia. We find that the credit access increases inorganic fertilizer use by 35 kilograms per household. We also find that the credit access increases the yield of teff by 37 percent but not the other major crops, such as 
maize and wheat. The lack of impact on little impacts on maize and wheat is are predictable given the low adoption rates of high-yielding varieties of maize and wheat, even among those households who receive the fertilizer credit. Only 20 percent of the maize producers adopt the high-yielding varieties of maize, and the adoption rate is about the same among wheat producers. Without fertilizer responsive high-yielding varieties, the fertilizer credit program can have only limited impacts on the crop yields and, hence, the farmers' incomes. Thus, consistent with Hypothesis 2 postulated in Chapter 1, Ethiopian farmers do respond to the availability of fertilizer credit through the government program by applying more fertilizer and producing more profitable crops, but the credit program has no significant impacts on net crop income per cultivated area and the per capita income.

The results raise a concern about the effectiveness of the credit program in Ethiopia in improving the living conditions of the farmers. First, the government must facilitate the development of private fertilizer markets to improve by reducing the government intervention in order to reduce the inefficient fertilizer delivery and quality poor fertilizer quality problems. Second, low responses to the fertilizer credit on crop yields should be addressed by the government. In the short term, to improve the returns to the credit program, the Ethiopian government needs to consider providing high-yielding varieties to farmers, along with the fertilizer credit. In particular, drought tolerant varieties should be provided because Ethiopian farmers suffer from frequent droughts in the country. Because the drought tolerant varieties are still new in the country, there is a need to conduct adoptive research on the new varieties so that the varieties will fit better with the local conditions. Furthermore, extension services should 
accompany the provisions of these materials. Without such complementary materials and services, the fertilizer credit program will have only limited impacts on farmers' welfare, and it would be difficult to continue operating such an expensive program without more tangible returns. 


\section{References}

Bonger, T., Ayele, G. \& Kumsa, T. (2004). Agricultural Extension, Adoption and Diffusion in Ethiopia. Ethiopian Development Research Institute (EDRI) Research Report, no.1, EDRI, Addis Ababa.

Conning, J. \& Udry, C. (2007). Financial Markets in Developing Countries. In R. Evenson and P. Pingali (Eds.), Handbook of Agricultural Economics, Volume 3, 2857-2908.

Croppenstedt, A., Demeke, M. \& Meschi, M. M. (2003). Technology Adoption in the Presence of Constraints: The Case of Fertilizer Demand in Ethiopia. Review of Development Economics, 7, 58-70.

Duflo, E., Kremer, M. \& Robinson, M. (2008). How High are Rates of Return to Fertilizer? Evidence from Field Experiments in Kenya. The American Economic Review 98, 482-488.

Feder, G., Just, R. E. \& Zilberman, D. (1985). Adoption of Agricultural Innovations in Developing Countries: A Survey. Economic Development and Cultural Change, 33, 255-98.

Gine, X. \& Klonner, S. (2006). Credit Constraints as a Barrier to Technology Adoption by the Poor: Lessons from South Indian Small-scale Fishery. Policy Research Working Paper Series 3665, The World Bank, Washington D.C.

Jayne, T. S., Govereh, J., Wanzala, M. \& Demeke, M. (2003). Fertilizer Market Development: A Comparative Analysis of Ethiopia, Kenya, and Zambia. Food Policy, 28, 293-316.

Munshi, K. (2007). Technology Diffusion. In Kaushik Basu (Ed.), Oxford Companion to Economics in India, New Delhi: Oxford University Press.

Spielman, D. J., Byerlee, D., Alemu, D. \& Kelemework, D. (2010). Policies to Promote Cereal Intensification in Ethiopia: The Search for Appropreate Public and Private Roles. Food Policy, 35, 185-194.

Zerfu, D. \& Larson, D. F. (2010). Incomplete Markets and Fertilizer Use: Evidence from Ethiopia, Policy Research Working Paper 5235, The World Bank, Washington D.C. 
Table 1. Characteristics of Sample Households

\begin{tabular}{lccccccc}
\hline & $\begin{array}{c}\text { Number of } \\
\text { Households }\end{array}$ & $\begin{array}{c}\text { Proportions of } \\
\text { Households who } \\
\text { Used Fertilizer }\end{array}$ & \multicolumn{2}{c}{$\begin{array}{c}\text { Proportions of } \\
\text { Fertilizer Users } \\
\text { who Obtained } \\
\text { Credit }\end{array}$} & $\begin{array}{c}\text { Inorganic Fertilizer } \\
\text { Use per ha } \\
\text { (kg/ha) }\end{array}$ \\
\cline { 2 - 8 } & & 2004 & 2006 & 2004 & 2006 & 2004 & 2006 \\
\hline & $(1)$ & $(2)$ & $(3)$ & $(4)$ & $(5)$ & $(6)$ & $(7)$ \\
\hline Amhara & 39 & 0.33 & 0.46 & 0.10 & 0.18 & 16.6 & 29.9 \\
Oromia & & & & & & & \\
Oromiya & 48 & 0.83 & 0.90 & 0.61 & 0.90 & 58.7 & 67.8 \\
South East & 134 & 0.91 & 0.91 & 0.77 & 0.86 & 120.8 & 108.9 \\
Central & 30 & 0.47 & 0.53 & 0.47 & 0.47 & 20.1 & 24.3 \\
West & 157 & 0.73 & 0.65 & 0.22 & 0.48 & 55.6 & 56.1 \\
SNNP & 408 & 0.75 & 0.74 & 0.46 & 0.63 & 71.0 & 69.8 \\
Total & & & & & & & \\
\hline
\end{tabular}


Table 2. Inorganic Fertilizer Use (kg/ha) by Access to Credit

\begin{tabular}{lccccc}
\hline & & \multicolumn{4}{c}{ Access to Credit in 2004 and 2006} \\
\cline { 2 - 6 } & All & \multicolumn{5}{c}{$\begin{array}{c}\text { Late } \\
\text { Ren } \\
\text { Recipients }\end{array}$} & $\begin{array}{c}\text { Early } \\
\text { (Received } \\
\text { Credit Only } \\
\text { in 2004) }\end{array}$ & $\begin{array}{c}\text { Recipients } \\
\text { (Received } \\
\text { Credit Only } \\
\text { in 2006) }\end{array}$ & $\begin{array}{c}\text { Continuous } \\
\text { Recipients }\end{array}$ \\
\cline { 2 - 6 } & $(1)$ & $(2)$ & $(3)$ & $(4)$ & $(5)$ \\
\hline Fertilizer Use (kg/ha) & 72.6 & 28.0 & 54.3 & 88.1 & 114.6 \\
in 2004 & 70.0 & 17.7 & 90.8 & 69.0 & 96.2 \\
Change: 2006-2004 & -2.7 & -10.3 & $36.5 * * *$ & -19.1 & -18.5 \\
Number of Households & 408 & 126 & 96 & 28 & 158 \\
\hline
\end{tabular}

Note: $* * *$ significant at $1 \%$ on the $t$-test for the difference in mean. 
Table 3. Crop Choice (\% of households) in 2004 and 2006 by Credit Access

\begin{tabular}{|c|c|c|c|c|c|}
\hline & \multirow[b]{2}{*}{ All } & \multicolumn{4}{|c|}{ Access to Credit in 2004 and 2006} \\
\hline & & $\begin{array}{c}\text { Non } \\
\text { Recipients }\end{array}$ & $\begin{array}{l}\text { Late } \\
\text { Recipients } \\
\text { (Received } \\
\text { Credit Only } \\
\text { in 2004) }\end{array}$ & $\begin{array}{c}\text { Early } \\
\text { Recipients } \\
\text { (Received } \\
\text { Credit Only } \\
\text { in 2006) }\end{array}$ & $\begin{array}{l}\text { Continuous } \\
\text { Recipients }\end{array}$ \\
\hline & $(1)$ & $(2)$ & (3) & (4) & $(5)$ \\
\hline \multicolumn{6}{|l|}{ Teff } \\
\hline 2004 & 0.43 & 0.26 & 0.41 & 0.58 & 0.54 \\
\hline 2005 & 0.51 & 0.28 & 0.50 & 0.48 & 0.71 \\
\hline \multicolumn{6}{|l|}{ HYV Maize } \\
\hline 2004 & 0.07 & 0.05 & 0.06 & 0.19 & 0.07 \\
\hline 2005 & 0.09 & 0.08 & 0.17 & 0.04 & 0.07 \\
\hline \multicolumn{6}{|l|}{ Local Maize } \\
\hline 2004 & 0.36 & 0.47 & 0.41 & 0.12 & 0.29 \\
\hline 2005 & 0.35 & 0.47 & 0.29 & 0.19 & 0.31 \\
\hline \multicolumn{6}{|l|}{ HYV Wheat } \\
\hline 2004 & 0.11 & 0.04 & 0.13 & 0.15 & 0.14 \\
\hline 2005 & 0.09 & 0.04 & 0.12 & 0.11 & 0.12 \\
\hline \multicolumn{6}{|l|}{ Local Wheat } \\
\hline 2004 & 0.40 & 0.21 & 0.44 & 0.39 & 0.52 \\
\hline 2005 & 0.37 & 0.14 & 0.38 & 0.44 & 0.54 \\
\hline Number of Households & 408 & 126 & 96 & 28 & 158 \\
\hline
\end{tabular}


Table 4. Crop Yields and Credit Access

\begin{tabular}{lcccc}
\hline \multirow{2}{*}{ Crop } & \multirow{2}{c}{ All } & \multicolumn{2}{c}{ Access to Credit } & Difference \\
\cline { 3 - 4 } & & without Credit & with Credit & $(3)-(2)$ \\
\cline { 2 - 4 } & $(1)$ & $(2)$ & $(3)$ & $(4)$ \\
\hline \multirow{2}{*}{ Teff } & 664.9 & 553.2 & 704.4 & $+151.2 * * *$ \\
HYV Maize & $(445.7)$ & $(396.2)$ & $(455.8)$ & {$[40.6]$} \\
& $1,800.6$ & $1,714.5$ & $1,838.3$ & +123.8 \\
Local Maize & $(1,382.7)$ & $(1550.4)$ & $(1318.5)$ & {$[364.1]$} \\
& $1,233.3$ & $1,309.3$ & $1,130.1$ & -179.2 \\
HYV Wheat & $(1,060.9)$ & $(1149.8)$ & $(920.5)$ & {$[115.8]$} \\
& $1,144.5$ & $1,080.6$ & $1,170.1$ & +89.5 \\
Local Wheat & $(769.1)$ & $(872.3)$ & $(730.1)$ & {$[186.6]$} \\
& 998.1 & 807.5 & $1,071.6$ & $+264.0 * * *$ \\
& $(794.7)$ & $(664)$. & $(828.9)$ & {$[78.8]$} \\
\hline
\end{tabular}

Note: $* * *$ significant at $1 \%$ on the $t$-test for the difference in mean. Numbers in parentheses are standard deviations, and numbers in brackets are standard errors. 
Table 5. Determinants of Access to Input Credit (Village FE Model ${ }^{\mathrm{a}}$ )

\section{Received Credit (=1)}

Log of Land Size (Ha)

0.745

Log of Asset Holdings (Birr)

Number of Cattle

Log of Soil Carbon Content

1 if Female-headed Household

Number of Family Members

Dependent Ratio ${ }^{\mathrm{b}}$

Household Head's Years of Schooling

Household Head's Age

Interaction Terms between Region and Survey Year

Dummies

Observations

Number of Groups (Year* Village)
$(2.05)^{* *}$

0.162

$-0.013$

$(0.71)$

$-0.740$

(0.99)

$-0.821$

$(2.46)^{* *}$

0.068

0.055

(0.10)

$-0.005$

0.001

$(0.15)$

Included

Note: Absolute value of $z$ scores in parentheses. $* *$ significant at $5 \%$.

${ }^{a}$ Conditional logit estimation with village*year fixed effects. ${ }^{b}$ Fraction of household members aged 0 to 15 or over 65 . 
Table 6. Determinants of Inorganic Fertilizer Application (Household FE Models)

\begin{tabular}{lcc}
\hline & \multicolumn{2}{c}{ Inorganic Fertilizer Application (kg/ha) } \\
\cline { 2 - 3 } & $(1)$ & $(2)$ \\
\hline Credit (=1) & 36.01 & 35.07 \\
& $(2.76)^{* * *}$ & $(2.62)^{* * *}$ \\
Log of Land Size (ha) & -45.96 \\
& & $(4.37)^{* * *}$ \\
Log of Asset Holdings (Birr) & 15.84 \\
& & $(3.75)^{* * *}$ \\
Number of Cattle & 0.367 \\
Number of Family Members & & $(1.18)$ \\
& & -4.957 \\
Interaction Terms between Region & Included & $(1.73)^{*}$ \\
and Survey Year Dummies & 782 & Included \\
\hline Observations & 402 & 773 \\
Number of Households & 0.05 & 402 \\
R-squared & & 0.13 \\
\hline Note: Absolute value of t statistics in parentheses. ${ }^{*}$ significant at $10 \%, * * *$ significant \\
at $1 \%$.
\end{tabular}


Table 7. Crop Yield (kg/ha in log) Models (Household FE Models)

\begin{tabular}{lccc}
\hline & Teff & Maize & Wheat \\
\cline { 2 - 4 } & $(1)$ & $(2)$ & $(3)$ \\
\hline & & & \\
Credit (=1) & 0.369 & 0.393 & 0.136 \\
& $(2.89)^{* *}$ & $(1.41)$ & $(1.09)$ \\
Log of Land Size (ha) & 0.032 & 0.355 & -0.058 \\
& $(0.16)$ & $(0.96)$ & $(0.29)$ \\
Log of Asset Holdings (Birr) & -0.005 & -0.102 & -0.028 \\
& $(0.08)$ & $(0.96)$ & $(0.38)$ \\
Number of Cattle & 0.006 & 0.008 & -0.000 \\
& $(1.43)$ & $(0.46)$ & $(0.09)$ \\
Number of Family Members & -0.089 & -0.051 & -0.066 \\
& $(1.65)$ & $(0.65)$ & $(1.37)$ \\
Constant & 7.086 & 7.003 & 7.205 \\
& $(7.75)^{* *}$ & $(4.96)^{* *}$ & $(8.66)^{* *}$ \\
Interaction Terms between & Included & Included & Included \\
Region and Survey Year & 582 & 385 & 565 \\
Dummies & 229 & 214 & 230 \\
\hline Observations & 0.11 & 0.09 & 0.06 \\
Number of Household ID & & & \\
R-squared & & & \\
\hline Note: Absolute value of robust t statistics in parentheses. & significant at $5 \%$ \\
\end{tabular}


Table 8. Crop Income Models (Household FE models)

$\log ($ Crop Income per ha)

(1)

\begin{tabular}{lc} 
Credit (=1) & -0.037 \\
Log of Land Size (ha) & $(0.35)$ \\
& -0.845 \\
Log of Asset Holdings (Birr) & 0.101 \\
& $(1.83)^{* * *}$ \\
Number of Cattle & 0.000 \\
& $(0.03)$ \\
Number of Family Members & -0.034 \\
& $(0.70)$ \\
Constant & 7.629 \\
Interaction Terms between Region & $(12.99)^{* * *}$ \\
and Survey Year dummies & Included \\
\hline Observations & 755 \\
Number of Household id & 398 \\
R-squared & 0.18 \\
\hline
\end{tabular}

Note: Absolute value of robust $\mathrm{t}$ statistics in parentheses. $*$ significant at $10 \%$, *** significant at $1 \%$ 